\title{
DOPRINOS ZNAČAJKI OSOBNOSTI I NEGATIVNIH ZDRAVSTVENIH PONAŠANJA NA DEPRESIVNOST, ANKSIOZNOST I STRES U RANOJ ODRASLOJ DOBI
}

\author{
ŽELJANA MILOVČIĆ, VESNA ANTIČEVIĆ, ANA ĆURKOVIĆ*
}

Cilj: Ciljevi rada bili su ispitati učestalost negativnih zdravstvenih ponašanja (konzumiranje alkohola, cigareta i kave) te ispitati povezanost između osobina ličnosti i tjelesne aktivnosti i izraženosti simptoma depresivnosti, anksioznosti i stresa.

Metode: Korišteni su sljedeći mjerni instrumenti: (a) upitnik općih podataka koji je sadržavao sociodemografska obilježja te pitanja o životnim navikama (konzumiranje alkohola i cigareta); (b) Skala depresivnosti, anksioznosti i stresa (DASS); (c) Big Five upitnik osobina ličnosti (BFI); (d) Međunarodni upitnik o tjelesnoj aktivnosti (IPAQ).

Rezultati: Rezultati istraživanja ukazuju kako značajno veći broj studenata ne konzumira cigarete nego što ih konzumira $(\chi 2=10,05, p<0,01)$, dok najveći broj studenata alkohol konzumira rijetko ili vikendom $(\chi 2=32,93, p<0,001)$. Kod studenata koji ne konzumiraju alkohol utvrđena je granično viša razina anksioznosti ( $t=1,63 ; p=0,053)$. Rezultati regresijske analize ukazuju na statistički značajan učinak neuroticizma na izraženost simptoma depresivnosti $(B=2,52, p<0,001)$ i anksioznosti $(B=3,09 p<0,001)$ kod studenata. Osobina ličnosti otvorenost prema iskustvima doprinosi većem stresu studenata $(B=0,1, p<0,001)$. Sjedilački način života utječe na pojavu anksioznosti $(B=0,001, p<0,05)$.

Zaključak: Prema dobivenim rezultatima možemo zaključiti da neuroticizam doprinosi pojavi simptoma anksioznosti i depresivnosti, otvorenost prema iskustvima većem stresu, dok sjedilački način života doprinosi višoj anksioznosti studenata.

Ključne riječi: ANKSIOZNOST, DEPRESIVNOST, OSOBINE LIČNOSTI, STRES, TJELESNA AKTIVNOST, NEGATIVNA ZDRAVSTVENA PONAŠANJA

\section{Uvod}

Osobine ličnosti možemo prikazati kao stabilne obrasce razmišljanja, osjećaja i ponašanja, a mogu se opisati kroz pet dimenzija koje uključuju neuroticizam (lako uznemiravanje, nemirnost, neprilagođenost), ekstraverziju (energičnost, asertivnost, pričljivost), savjesnost (odgovornost, pouzdanost, urednost), otvorenost prema iskustvima (maštovitost, intelektualnost, neovisan um) i ugodnost (kooperativnost, povjerljivost, dobrodušnost) (1).

Anksioznost i depresivnost jedni su od najčešćih simptoma psihičkih smet-

*Sveučilište u Splitu,

Sveučilišni odjel zdravstvenih studija

Adresa za dopisivanje:

Prof. dr. sc. Vesna Antičević

Sveučilište u Splitu

Sveučilišni odjel zdravstvenih studija

21000 Split, Ruđera Boškovića 35

E-mail: vanticevic.ozs@gmail.com nji, na koje osobine ličnosti mogu imati utjecaj te predisponirati pojavu simptoma $(2,3)$. Studije pokazuju pozitivnu povezanost ekstraverzije i neuroticizma s depresivnim i anksioznim poremećajima te je utvrđeno kako osobe s težim anksioznim poremećajima pokazuju više razine neuroticizma i introverzije (4-8). Studije također pokazuju niske razine savjesnosti i ugodnosti kod osoba s anksioznim i depresivnim poremećajima $(5,7)$.

Studenti medicinskih i zdravstvenih usmjerenja specifična su skupina studenata i, kao i kod medicinskih i zdravstvenih djelatnika, rezultati pojedinih studija pokazuju povećanje razina stresa razmjerno $\mathrm{s}$ povećanjem razdoblja studiranja te povećan rizik za pojavu sindroma sagorijevanja (9-13). Prema nekim rezultatima stopa prevalencije anksioznosti i depresivnosti je čak i veća među populacijom studenata sestrinstva nego u općoj populaciji (14). Specifičnost studentske populacije, i općenito adoles- centske populacije, jest što rijetko imaju tendenciju potražiti pomoć kod pojave simptoma psihičkih poremećaja, što se posebno odnosi na studente medicinskih i zdravstvenih usmjerenja $(9,15)$. Zbog toga problem psihičkih poremećaja kod ove populacije predstavlja značajan javnozdravstveni problem.

Za studentsku i adolescentsku populaciju specifičan je i karakterističan životni stil u kojem su nerijetko zastupljena i negativna zdravstvena ponašanja kao što su pušenje, konzumacija alkohola i pretežno sjedilačka tjelesna aktivnost. Ovakva ponašanja često mogu biti povezana s psihičkim smetnjama. Različite studije pokazuju pozitivnu povezanost pušenja i psihičkih poremećaja (16, 17). Pojedinci s anksioznim i depresivnim poremećajima često više puše kako bi ublažili simptome te u tom slučaju psihički poremećaji dovode do više pušenja, ali pušenje može i dovesti do većeg razvoja psihičkih poremećaja pogoršavaju- 
ći početne simptome (18-21). Kao i kod pušenja, pojedinci često pribjegavaju i konzumaciji alkohola kako bi ublažili simptome stresa, pa je tako i kod populacije studenata $\mathrm{i}$ adolescenata utvrđena pozitivna povezanost povećane i češće konzumacije alkohola s povećanim razinama depresivnosti i anksioznosti (22-26). S druge strane, utvrđen je pozitivan učinak redovne tjelesne aktivnosti na psihičko stanje u smislu umanjivanja stresa i razina anksioznosti (27-29).

U ovom istraživanju glavni ciljevi rada bili su ispitati učestalost negativnih zdravstvenih ponašanja (konzumiranje, alkohola, cigareta $\mathrm{i}$ kave) studenata zdravstvenih studija te ispitati prognostički značaj osobina ličnosti i tjelesne aktivnosti za razine izraženosti depresivnosti, anksioznosti i stresa kod studenata 3. godine preddiplomskih studija.

\section{Materijali i metode}

\section{Sudionici i postupak}

Istraživanje je provedeno na Sveučilišnom odjelu zdravstvenih studija Sveučilišta u Splitu. Sudionici su bili studenti treće, završne godine preddiplomskih studija te je, uz odaziv od $79 \%$, uzorak bio sačinjen od 78 studenata. Prosječna dob ispitanika bila je 22 godine $\mathrm{s}$ interkvartilnim rasponom od 2 godine ( $\mathrm{IQR}=21,00-23,00)$. U uzorku su prevladavali sudionici ženskog spola $(84,6 \%)$. Istraživanje je provedeno u akademskoj godini 2019./2020. te su podatci prikupljeni primjenom upitnika tijekom nastave, uz prethodno objašnjenje svrhe istraživanja. Sudjelovanje u istraživanju je bilo dobrovoljno, a identitet sudionika istraživačima nije bio poznat. Istraživanje je odobrilo Etičko povjerenstvo Sveučilišnog odjela zdravstvenih studija Sveučilišta u Splitu (2181-228-07-200027).

\section{Mjerni instrumenti}

Upitnik općih podataka, sastavljen za potrebe ovog istraživanja, sadržavao je pitanja o sociodemografskim obilježjima ispitanika (spol, dob), studijskom smjeru te o životnim navikama koje uključuju negativna zdravstvena pona- šanja (konzumiranje kave, alkohola i cigareta).

Skala depresivnosti, anksioznosti i stresa (DASS) sastoji se od 21 čestice, podijeljene u 3 podskale, od kojih svaka ima 7 čestica na koje sudionici odgovaraju na skali 0-3, od "uopće se ne odnosi na mene" do "u potpunosti se odnosi na mene". Podskala depresivnosti se odnosi na simptome beznadnosti, disforije, apatije, vlastitog obezvrjeđivanja i nedostatka interesa ("Osjećam se tužno i potišteno"). Podskala anksioznosti se odnosi na situacijsku anksioznost i pobuđenost autonomnog sustava ("Suše mi se usta"). Podskala stresa ukazuje na poteškoće opuštanja, kroničnu nespecifičnu pobuđenost, nestrpljenje, uznemirenost, i sl. ("Toliko se uznemirim u nekim situacijama da osjetim golemo olakšanje kada prođu"). Koeficijent pouzdanosti za podskalu depresivnosti iznosi 0,71, za podskalu anksioznosti 0,79 te za podskalu stresa koeficijent pouzdanosti iznosi 0,81 (30). Ispitanici su odgovarali zaokruživanjem odgovarajućega broja na skali Likertova tipa od 4 stupnja. Korišten je validirani hrvatski oblik skale gdje je potvrđena trofaktorska struktura izvornika te su na uzorku odraslih ispitanika utvrđeni koeficijent unutarnje pouzdanosti za podskalu depresivnosti 0,93, anksioznosti 0,81 te za podskalu stresa 0,89 (31).

BFI (Big Five Inventory) upitnik ličnosti koristi se za mjerenje dimenzije pet-faktorskog modela ličnosti. Upitnik se sastoji od 44 tvrdnje, a opisuje 5 velikih dimenzija ličnosti: ekstraverziju ("Sebe vidim kao osobu koja je pričljiva"), neuroticizam ("Sebe vidim kao osobu koja može biti napeta"), savjesnost ("Sebe vidim kao osobu koja temeljito obavlja posao"), ugodnost ("Sebe vidim kao osobu koja je prema gotovo svima pažljiva i ljubazna") i otvorenost ("Sebe vidim kao osobu koja je radoznala i zanimaju ju brojne različite stvari”). Ispitanici su odgovarali zaokruživanjem odgovarajućeg broja na skali Likertova tipa od 5 stupnjeva. Pouzdanost pojedinih dimenzija mjerenih BFI upitnikom izražena je Cronbachovim alfa koeficijentom, a u prosjeku za sve dimenzije se kreće oko 0,80 , a test-retest pouzdanost iznosi 0,85 (32).
Međunarodni upitnik o tjelesnoj aktivnosti (International Physical Activity Questionnaire - Short Form, IPAQ SF) ispituje različite vrste tjelesne aktivnosti kojima se ljudi svakodnevno bave. Pitanja ispituju intenzitet tjelesne aktivnosti u posljednjih 7 dana u rasponu od intenzivne tjelesne aktivnosti, umjerene tjelesne aktivnosti, hodanja i sjedenja (33). Temeljem odgovora ispitanika o učestalosti tjelesne aktivnosti tijekom posljednjih 7 dana, računaju se tzv. MET-minute/tjedan za svaku od razina tjelesne aktivnosti. Temeljem MET minuta ispitanici se dijele $u$ pripadajuće kategorije tjelesne aktivnosti: intenzivna, umjerena i niska (34).

Pri statističkoj obradi podataka korištene su metode deskriptivne statistike: aritmetičke sredine i standardne devijacije za normalno distribuirane varijable te, u slučaju odstupanja od normalne razdiobe, medijan kao srednja vrijednost i interkvartilni raspon kao pokazatelj odstupanja od srednjih vrijednosti. Povezanost među varijablama ispitivala se Pearsonovim koeficijentom korelacije, dok se utjecaj osobina ličnosti i tjelesne aktivnosti na anksioznost, stres i depresivnost ispitivao linearnom regresijom. Pri analizi i obradi podataka korišten je statistički paket SPSS 25.

\section{Rezultati}

Pri ispitivanju negativnih zdravstvenih ponašanja zabilježeno je kako u uzorku prevladavaju nepušači kojih je dvostruko više od pušača, te je utvrđena i statistički značajna razlika u broju pušača i nepušača $(\chi 2=10,05$; $\mathrm{p}<0,01)$. Srednja vrijednost pušačkog staža studenata pušača je 6,00 godina $s$ interkvartilnim rasponom od 5 godina $(\mathrm{IQR}=4,00-9,00)$, dok je srednja vrijednost broja cigareta dnevno $10,00 \mathrm{~s}$ interkvartilnim rasponom od 11 cigareta $(\mathrm{IQR}=4,00-15,00)$. Iako je ispitivanjem zabilježeno kako je u uzorku više studenata koji konzumiraju alkohol od onih koji ga ne konzumiraju (1,36 puta više), nije utvrđena statistički značajna razlika između konzumenata i nekonzumenata $(\chi 2=1,85 ; p>0,05)$. Međutim, utvrđena je statistički značajna razlika u učestalosti ispijanja alkohola među studentima 
Tablica 1.

Učestalost negativnih zdravstvenih ponašanja studenata

\begin{tabular}{|c|c|c|c|}
\hline Negativna ponašanja & $\mathrm{N}$ & $\chi^{2}$ & $\mathrm{p}^{*}$ \\
\hline Pušači & 25 & 10,05 & $0,002 * *$ \\
\hline \multicolumn{4}{|l|}{ Nepušači } \\
\hline Konzumiraju alkohol & 45 & 1,85 & 0,174 \\
\hline Ne konzumiraju alkohol & 33 & & \\
\hline Konzumira alkohol rijetko & 32 & 32,93 & $<0,001 * *$ \\
\hline Konzumira alkohol svaki dan & 1 & & \\
\hline Konzumira alkohol vikendom & 12 & & \\
\hline Konzumiraju kavu & 66 & 37,38 & $<0,001 * *$ \\
\hline Ne konzumiraju kavu & 12 & & \\
\hline Učestalost negativnih ponašanja & Med & IQR & \\
\hline Pušački staž & 6,00 & $(4,00-9,00)$ & \\
\hline Broj cigareta dnevno & 10,00 & $(4,00-15,00)$ & \\
\hline Broj šalica kave dnevno & 2,00 & $(1,00-2,00)$ & \\
\hline
\end{tabular}

Med - medijan; IQR - interkvartilni raspon; ${ }^{*} \mathrm{p}<0,05 ; * * \mathrm{p}<0,01$

Tablica 2 .

Prikaz povezanosti između dimenzija ličnosti mjerenih BFI upitnikom

\begin{tabular}{lllll}
\hline & Ekstraverzija & Ugodnost & Savjesnosti & Neuroticizam \\
\hline Ugodnost & $-0,11$ & & \\
Savjesnosti & $0,23^{*}$ & $0,38^{* *}$ & \\
Neuroticizam & $-0,45^{* *}$ & $-0,14$ & $-0,36^{* *}$ & \\
Otvorenost & $0,46^{* *}$ & $-0,04$ & 0,20 & $-0,11$ \\
\hline
\end{tabular}

$\mathrm{r}$ - Pearsonov koeficijent korelacije; ${ }^{*} \mathrm{p}<0,05 ; * * \mathrm{p}<0,01$

koji konzumiraju alkohol, pri čemu se većina studenata izjasnila kako alkohol konzumira rijetko ili samo tijekom vikenda $(\chi 2=32,93 ; p<0,001)$. Pri ispitiva- ispitivanju tjelesne aktivnosti studenata utvrđena je pretežno sjedilačka aktivnost pri kojoj su studenti u proteklih 7 dana proveli u prosjeku najviše vremena (1737,13 $\pm 935,71$ minuta).

Pri ispitivanju osobina ličnosti utvrđeno je kako su u našem uzorku ispitanika najizraženije osobine savjesnosti (prosjek 3,79 $\pm 0,57$ ) i ugodnosti (prosjek $3,69 \pm 0,51$ ), dok je najmanje izražena osobina neuroticizam (prosjek 2,70 $\pm 0,45$ ). Utvrđena je pozitivna i statistički značajna povezanost između osobina ekstraverzije i savjesnosti $(r=0,229 ; p=0,044)$, ekstraverzije i otvorenosti $(\mathrm{r}=0,455$; $\mathrm{p}<0,001)$, te ugodnosti $\mathrm{i}$ savjesnosti $(r=0,376 ; p=0,001)$. Negativna statistički značajna povezanost utvrđena je između osobina ekstraverzije i neuroticizma $(\mathrm{r}=$ $0,454 ; p<0,001)$, te savjesnosti i neuroticizma ( $\mathrm{r}=-0,358 ; \mathrm{p}=0,001)$ (Tablica 2). Iz navedenog možemo zaključiti kako su studenti koji pokazuju više stupnjeve ekstraverzije ujedno i savjesniji i otvoreniji prema novim iskustvima te manje neurotični, dok su savjesniji studenti ugodniji u kontaktima i manje neurotični.

Pri ispitivanju depresivnosti, anksioznosti i stresa utvrđeno je kako je najviša prosječna vrijednost na podskali stresa $(6,14 \pm 4,48)$, a najmanja na podskali depresivnosti $(3,04 \pm 3,27)$. Utvrđen je statistički značajan pozitivan doprinos neuroticizma na depresivnost $(\mathrm{B}=2,52$, $\mathrm{p}<0,001)$ i anksioznost $(\mathrm{B}=3,09, \mathrm{p}<0,001)$ , te otvorenosti na intenzitet stresa $(\mathrm{B}=0,01, \mathrm{p}<0,001)$. Drugim riječima, studenti koji imaju više bodova na skali neuroticizma i emocionalne nestabilnosti imat će izraženije simptome anksioznosti i depresivnosti, dok će veća otvo-

Tablica 3.

Predviđanje simptoma depresivnosti, anksioznosti i stresa temeljem dimenzija ličnosti

\begin{tabular}{|c|c|c|c|c|c|c|c|c|c|}
\hline & \multicolumn{3}{|c|}{ Depresivnost } & \multicolumn{3}{|c|}{ Anksioznost } & \multicolumn{3}{|c|}{ Stres } \\
\hline & B & $\mathrm{t}$ & $\mathrm{p}$ & B & $\mathrm{t}$ & $\mathrm{p}$ & B & $\mathrm{t}$ & $\mathrm{P}$ \\
\hline Ekstraverzija & $-0,01$ & $-0,02$ & 0,987 & $-0,14$ & $-0,19$ & 0,850 & $-0,76$ & 0,33 & 0,74 \\
\hline Ugodnost & 0,30 & 0,45 & 0,658 & 0,53 & 0,62 & 0,540 & $-0,37$ & $-1,06$ & 0,29 \\
\hline Savjesnost & $-1,01$ & $-1,65$ & 0,104 & $-0,34$ & $-0,42$ & 0,680 & $-0,63$ & $-0,43$ & 0,67 \\
\hline Neuroticizam & 2,52 & 4,48 & $<0,001 * *$ & 3,09 & 4,31 & $<0,001^{* *}$ & 3,82 & $-0,77$ & 0,44 \\
\hline Otvorenost & $-0,09$ & $-0,12$ & 0,908 & $-0,46$ & $-0,46$ & 0,650 & 0,10 & 5,35 & $<0,001 * *$ \\
\hline
\end{tabular}

b - nestandardizirani beta koeficijent; ${ }^{*} \mathrm{p}<0,05 ; * * \mathrm{p}<0,01$ 
Tablica 4.

Predviđanje depresivnosti, anksioznosti i stresa temeljem prakticiranja tjelesne aktivnosti

\begin{tabular}{|c|c|c|c|c|c|c|c|c|c|}
\hline & \multicolumn{3}{|c|}{ Depresivnost } & \multicolumn{3}{|c|}{ Anksioznost } & \multicolumn{3}{|c|}{ Stres } \\
\hline & B & $\mathrm{t}$ & $\mathrm{p}$ & $\mathrm{B}$ & $\mathrm{t}$ & $\mathrm{P}$ & $\mathrm{B}$ & $\mathrm{t}$ & $\mathrm{P}$ \\
\hline Izrazito naporna aktivnost & 0,00 & 0,02 & 0,986 &, 002 & 1,04 & 0,30 & 0,003 & 1,71 & 0,092 \\
\hline Umjerena tjelesna aktivnost & 0,00 & $-0,31$ & 0,755 &, 000 & $-0,25$ & 0,80 & $-0,001$ & $-0,48$ & 0,631 \\
\hline Hodanje & 0,00 & $-0,60$ & 0,551 & 0,001 & 0,60 & 0,55 & 0,00 & 0,13 & 0,896 \\
\hline Sjedenje & 0,001 & 1,53 & 0,130 & 0,001 & 2,31 & $0,024 *$ & 0,00 & 0,90 & 0,373 \\
\hline
\end{tabular}

b - nestandardizirani beta koeficijent; ${ }^{*} \mathrm{p}<0,05 ; * * \mathrm{p}<0,01$

renost prema iskustvima predviđati više razine stresa kod studenata (Tablica 3).

Pri ispitivanju utjecaja tjelesne aktivnosti na depresivnost, anksioznost i stres utvrđena je statistički značajna povezanost između sjedilačke aktivnosti i simptoma anksioznosti, koja ukazuje kako studenti koji više vremena provode sjedeći imaju više razine anksioznosti. Rezultati pokazuju kako s porastom vremena provedenog u sjedenju dolazi do porasta razine anksioznosti $\mathrm{u}$ prosjeku za 0,001 bod $(\mathrm{B}=0,001, \mathrm{p}<0,05)$. Ovim rezultatom potvrđen je učinak tjelesne aktivnosti na anksioznost, dok učinak tjelesne aktivnosti na stres i depresivnost nije utvrđen (Tablica 4).

Pri ispitivanju utjecaja negativnih zdravstvenih ponašanja (konzumiranja alkohola, cigareta i kave) na depresivnost, anksioznost i stres, nije utvrđena statistički značajna povezanost ni kod jednog parametra.

\section{Rasprava}

Rezultati ovog istraživanja ukazuju na umjereni stupanj izraženosti negativnih zdravstvenih ponašanja kod studenata zdravstvenih studija. Među studentima prevladavaju nepušači. Iako značajno veći broj studenata konzumira alkohol u odnosu na one koji ga ne konzumiraju, učestalost konzumiranja je rijetka ili ograničena na vikende. S obzirom da se radi o uzorku studenata završne godine preddiplomskih studija, koji su već dobro upoznati sa štetnostima negativnih zdravstvenih ponašanja i korištenjem pozitivnih zdravstvenih ponašanja s ciljem prevencije bolesti, ovakvi rezultati nisu u potpunosti zadovoljavajući.
Što se tiče utjecaja zdravstvenih ponašanja na pojavu psihičkih smetnji, utvrđeni su štetni učinci prekomjernog sjedenja i smanjene tjelesne aktivnosti na pojavu anksioznosti kod studenata. Ovakav rezultat je u skladu s drugim istraživanjima koja su pokazala povezanost smanjene tjelesne aktivnosti s pojavom anksioznosti te pozitivan utjecaj redovne tjelesne aktivnost na psihičko stanje i smanjene razine anksioznosti $(27,29$, 35).

Od varijabli negativnog afektiviteta, u ovom se istraživanju ističe najviša zastupljenost stresa, dok su anksioznost i depresivnost kod studenata izraženi u manjoj mjeri. Ovakav je rezultat u skladu s istraživanjima koja pokazuju kako su studenti medicinskih i zdravstvenih usmjerenja podložni stresu i sindromu sagorijevanja, koji su kod njih prisutniji nego u općoj populaciji (9-14). Također je potvrđeno kako je razina stresa kod ove specifične populacije studenata veća na višim godinama studija, a i u našem se istraživanju radi o studentima završne godine preddiplomskih studija, kod kojih je stoga i očekivano da imaju povećane razine stresa (9-13).

Naše istraživanje je također potvrdilo prediktivnu ulogu neuroticizma kao osobine ličnosti za pojavu depresivnosti i anksioznosti. Ovakav rezultat je u skladu s rezultatima prethodnih istraživanja koja su također utvrdila pozitivnu povezanost između neuroticizma i pojave anksioznosti, te potvrdila više razine neuroticizma kod osoba s težim anksioznim poremećajima (4-8). Ovakav rezultat je očekivan dijelom jer osobe s većom emocionalnom nestabilnošću imaju osjetljiviji tip živčanog sustava koji je osjetljiviji na vanjske podražaje, pa se simptomi anksioznosti kod takvih osoba pojavljuju češće nego kod emocionalno stabilnijih ljudi.

Od ostalih osobina ličnosti rezultati su pokazali pozitivnu povezanost otvorenosti i stresa. Ovakav bi se rezultat možda mogao objasniti time što zainteresiranost za različite životne sadržaje, učenje novih vještina $\mathrm{i}$ angažiranje $\mathrm{u}$ velikom broju aktivnosti, koji su inače karakteristični za studentsku i adolescentsku populaciju, pridonose održavanju viših razina stresa.

Ovo istraživanje ima i nekoliko ograničenja. Jedno od ograničenja istraživanja je veličina uzorka, jer, iako sa stopom odaziva od $79 \%$ adekvatno prikazuje odabranu populaciju, uzorak od 78 ispitanika je i dalje malen te bi daljnja istraživanja na većem broju ispitanika omogućila reprezentativniji uzorak i sigurnije zaključke. Dodatno je ograničenje i činjenica kako je istraživanje provedeno na specifičnoj studentskoj populaciji, pa je upitno koliko su rezultati primjenjivi na opću populaciju. Također, upitnici u kojima ispitanici sami ocjenjuju svoje stanje imaju ograničenu dijagnostičku vrijednost te bi psihološki intervjui $\mathrm{s}$ ispitanicima povećali vrijednost naših rezultata.

\section{NOVČANA POTPORA/FUNDING} Nema/None

ETIČKO ODOBRENJE/ETHICAL APPROVAL Nije potrebno/None

SUKOB INTERESA/CONFLICT OF INTEREST Autori su popunili the Unified Competing Interest form na www.icmje.org/coi_disclosure.pdf (dostupno na zahtjev) obrazac i izjavljuju: nemaju 
potporu niti jedne organizacije za objavljeni rad; nemaju financijsku potporu niti jedne organizacije koja bi mogla imati interes za objavu ovog rada u posljednje 3 godine; nemaju drugih veza ili aktivnosti koje bi mogle utjecati na objavljeni rad./ All authors have completed the Unified Competing Interest form at www.icmje.org/coi_disclosure. pdf (available on request from the corresponding author) and declare: no support from any organization for the submitted work; no financial relationships with any organizations that might have an interest in the submitted work in the previous 3 years; no other relationships or activities that could appear to have influenced the submitted work.

\section{LITERATURA}

1. Koorevaar AM, Comijs HC, Dhondt AD, van Marwijk HW, van der Mast RC, Naarding P, et al. Big Five personality and depression diagnosis, severity and age of onset in older adults. J Affect Disord. 2013; 151 (1): 178-85.

2. Abrignani MG, Renda N, Abrignani V, Raffa A, Novo S, Baido RL. Panic disorder, anxiety, and cardiovascular diseases. Clin Neuropsychiatry. 2014; 11: 130-44.

3. Hettema JM. What is the genetic relationship between anxiety and depression? Am J Med Genet C Semin Med Genet. 2008; 148C (2): $140-6$.

4. Bienvenu OJ, Nestadt G, Samuels JF, Costa PT, Howard WT, Eaton WW. Phobic, panic, and major depressive disorders and the five-factor model of personality. J Nerv Ment Dis. 2001; 189 (3): 154-61.

5. Bienvenu OJ, Samuels JF, Costa PT, Reti IM, Eaton WW, Nestadt G. Anxiety and depressive disorders and the five-factor model of personality: a higher- and lower-order personality trait investigation in a community sample. Depress Anxiety. 2004; 20 (2): 92-7.

6. Newbury-Birch D, Kamali F. Psychological stress, anxiety, depression, job satisfaction, and personality characteristics in preregistration house officers. Postgrad Med J. 2001; 77 (904): 109-11.

7. Nouri F, Feizi A, Keshteli AH, Roohafza H, Afshar H, Adibi P. Personality traits are differently associated with depression and anxiety: Evidence from applying bivariate multiple binary logistic regression on a large sample of general adults. Psychiatr Danub. 2019; 31 (4): 448-56.

8. Røvik JO, Tyssen R, Gude T, Moum T, Ekeberg $\varnothing$, Vaglum P. Exploring the interplay between personality dimensions: A comparison of the typological and the dimensional approach in stress research. Pers Individ Dif. 2007; 42: 1255-66.

9. Dahlin ME, Runeson B. Burnout and psychiatric morbidity among medical students entering clinical training: a three year prospective questionnaire and interview-based study. BMC Med Educ. 2007; 7: 6.
10. Deary IJ, Watson R, Hogston R. A longitudinal cohort study of burnout and attrition in nursing students. J Adv Nurs. 2003; 43 (1): 71-81.

11. Tyssen R, Dolatowski FC, Rovik JO, Thorkildsen RF, Ekeberg O, Hem E, et al. Personality traits and types predict medical school stress: a six-year longitudinal and nationwide study. Med Educ. 2007; 41 (8): 781-7.

12. Warbah L, Sathiyaseelan M, Vijayakumar C, Vasantharaj B, Russell S, Jacob KS. Psychological distress, personality, and adjustment among nursing students. Nurse Educ Today. 2007; 27 (6): 597-601.

13. Lo R. A longitudinal study of perceived level of stress, coping and self-esteem of undergraduate nursing students: an Australian case study. J Adv Nurs. 2002; 39 (2): 119-26.

14. Dyrbye LN, Thomas MR, Shanafelt TD. Systematic review of depression, anxiety, and other indicators of psychological distress among U.S. and Canadian medical students. Acad Med. 2006; 81 (4): 354-73.

15. Gulliver A, Griffiths KM, Christensen H. Perceived barriers and facilitators to mental health help-seeking in young people: a systematic review. BMC Psychiatry. 2010; 10: 113.

16. Farrell M, Howes S, Taylor C, Lewis G, Jenkins R, Bebbington P, et al. Substance misuse and psychiatric comorbidity: an overview of the OPCS National Psychiatric Morbidity Survey. Addict Behav. 1998; 23 (6): 909-18.

17. Meltzer H, Gill B, Hinds K, Petticrew M. Economic Activity and Social Functioning of Residents With Psychiatric Disorders. London: HMSO; 1996.

18. Chaiton MO, Cohen JE, O'Loughlin J, Rehm J. A systematic review of longitudinal studies on the association between depression and smoking in adolescents. BMC Public Health. 2009; 9: 356.

19. Boden JM, Fergusson DM, Horwood LJ. Cigarette smoking and depression: tests of causal linkages using a longitudinal birth cohort. $\mathrm{Br} \mathrm{J}$ Psychiatry. 2010; 196 (6): 440-6.

20. Taylor G, McNeill A, Girling A, Farley A, Lindson-Hawley N, Aveyard P. Change in mental health after smoking cessation: systematic review and meta-analysis. BMJ. 2014; 348: g1151.

21. Munafo MR, Araya R. Cigarette smoking and depression: a question of causation. $\mathrm{Br} \mathrm{J}$ Psychiatry. 2010; 196 (6): 425-6.

22. Townsend TG C-AD. Internalizing disorders among adolescents: A risk for subsequent substance use. In: R R, editor. Clinical Handbook of Adolescent Addiction: Oxford: WileyBlackwell; 2013; 161-9.

23. Tomlinson KL, Brown SA. Self-medication or social learning? A comparison of models to predict early adolescent drinking. Addict Behav. 2012; 37 (2): 179-86.
24. Johannessen EL, Andersson HW, Bjorngaard JH, Pape K. Anxiety and depression symptoms and alcohol use among adolescents - a cross sectional study of Norwegian secondary school students. BMC Public Health. 2017; 17 (1): 494.

25. Zimmermann P, Wittchen HU, Hofler M, Pfister H, Kessler RC, Lieb R. Primary anxiety disorders and the development of subsequent alcohol use disorders: a 4-year community study of adolescents and young adults. Psychol Med. 2003; 33 (7): 1211-22.

26. Frojd S, Ranta K, Kaltiala-Heino R, Marttunen M. Associations of social phobia and general anxiety with alcohol and drug use in a community sample of adolescents. Alcohol Alcohol. 2011; 46 (2): 192-9.

27. Diener E, Chan MY. Happy people live longer: Subjective well-being contributes to health and longevity. Applied Psychology: Health and Well-Being. 2011; 3 (1): 1-43.

28. Salmon P. Effects of physical exercise on anxiety, depression, and sensitivity to stress. Clinical Psychology Review. 2001; 21 (1): 33-61.

29. De Moor MH, Beem AL, Stubbe JH, Boomsma DI, De Geus EJ. Regular exercise, anxiety, depression and personality: a population-based study. Prev Med. 2006; 42 (4): 273-9.

30. Lovibond PF, H. LS. The structure of negative emotional states: Comparison of the Depression Anxiety Stress Scales (DASS) with the Beck Depression and Anxiety Inventories. Behaviour Research and Therapy. 1995; 33: 335-43.

31. Lovibond SH, Lovibond PF. Skale depresije, anksioznosti i stresa DASS-S i DASS-O. Priručnik. - hrvatsko izdanje. 2019.

32. Karažija A. Osobine ličnosti osoba s tjelesnim modifikacijama. Zagreb: Filozofski fakultet; 2015.

33. Ajman H, Đapić Štriga S, Novak D. Pouzdanost kratke verzije međunarodnog upitnika tjelesne aktivnosti za Hrvatsku. Hrvat športskomed vjesn 2015; 30: 87-90.

34. Ainsworth BE, Haskell WL, Whitt MC, Irwin ML, Swartz AM, Strath SJ, et al. Compendium of physical activities: an update of activity codes and MET intensities. Med Sci Sports Exerc. 2000; 32 (9): S498-504.

35. Richardson N. The effects of physical activity on perceived stress, anxiety and life satisfaction. Dublin: Dublin business school 2014. 
Summary

THE CONTRIBUTION OF PERSONALITY AND NEGATIVE HEALTH BEHAVIOURS ON DEPRESSION, ANXIETY AND STRESS DURING EARLY ADULTHOOD

Željana Milovčić, Vesna Antičević, Ana Ćurković

Aims: The aims of the study were to examine the frequency of negative health behaviors (alcohol, cigarette and coffee consumption) and to examine association between personality traits and physical activity with the symptoms of depression, anxiety and stress.

Methods: The following measures were used: (a) a general data questionnaire containing sociodemographic characteristics and questions about unhealthy life habits (alcohol and cigarette consumption); (b) Depression, Anxiety and Stress Scale (DASS); (c) Big Five Personality Trait Questionnaire (BFI); (d) International Physical Activity Questionnaire (IPAQ).

Results: The results indicated a significantly higher number of students who did not consume cigarettes $(\chi 2=10.05, p<0.01)$, while the largest number of students consumed alcohol infrequently or on weekends $(\chi 2=32.93, p<0.001)$. Marginally higher levels of anxiety were found in students who did not consume alcohol $(t=1.63 ; p=0.053)$. The results of regression analysis indicated a statistically significant effect of neuroticism on the intensity of depressive $(B=2.52, p<0.001)$ and anxiety $(B=3.09 p<0.001)$ symptoms in students. Openness to experiences contributed to higher student stress levels $(B=0.1, p<0.001)$. Sedentary lifestyle affects the occurrence of anxiety $(B=0.001, p<0.05)$.

Conclusion: According to the obtained results, we can conclude that neuroticism contributes to the appearance of symptoms of anxiety and depression, openness to experiences to higher stress levels, while a sedentary lifestyle contributes to higher anxiety of students.

\section{Keywords: ANXIETY, DEPRESSION, PERSONALITY TRAITS, STRESS, PHYSICAL ACTIVITY, NEGATIVE HEALTH BEHAVIORS}

Primljeno/Received: 21. 7. 2021.

Prihvaćeno/Accepted: 3. 10. 2021. 